\title{
UAV-BASED PHOTOGRAMMETRY FOR ARCHAEOLOGICAL HERITAGE SITE SURVEY AND 3D MODELING OF THE SARDUS PATER TEMPLE (ITALY)
}

\author{
V. Bagnolo ${ }^{1, *}$, N. Paba ${ }^{1}$ \\ ${ }^{1}$ DICAAR, University of Cagliari, Faculty of Engineering and Architecture, Cagliari (CA), Italy - vbagnolo@unica.it \\ nicola.paba@gmail.com
}

Commission II

KEY WORDS: UAV Photogrammetry, Structure-from-Motion (SfM), Archaeological Heritage, 3D modelling, Orthophoto, Roman temple.

\begin{abstract}
:
Despite the high standard guaranteed by 3D scanning technology, image based modeling establishes the most widely used technique for surface reconstruction, being a cheaper and more portable approach. The strong increase in the use of Unmanned Aerial Vehicles (UAVs), is increasingly affirming and consolidating over the years. Being more cheap and portable than the active sensors approach, the combination of photogrammetry and drones is widely used for different applications both for large scale mapping and for documentation of architecture and archaeological heritage. UAV based photogrammetry allows for rapid accurate mapping and three-dimensional modelling. Over the last two decades, the study of archaeological sites have benefited from the constant evolution of sensor-based surveying techniques, finding effective application for purely visualization purposes or for the extraction of metric data. The Punic-Roman temple "Sardus Pater Babai" in southern Sardinia (Italy), has been the subject of a massive anastylosis. The close-range photogrammetry technique, exploiting the images produced by a UAV consumer and the GNSS system data, has allowed the creation of metrically correct $2 \mathrm{D}$ and $3 \mathrm{D}$ models useful also for an effective visualization of the information. A series of orthoimages has been extracted in order to represent plan, elevations and cross-sections of the monument.
\end{abstract}

\section{INTRODUCTION}

The technological development of UAVs, computers and processing software has made close-range photogrammetry a very effective Low-Cost system for surveying techniques (Fernandez-Hernandez et al 2015). By reducing the costs of drones, today it is possible to achieve excellent quality results even with the so-called "consumer drones", bolstered by the high quality attainable even with low-cost equipment (Westoby et al., 2012).

The use of drones, on its own or integrated with ground obtained information such as photographic or TLS systems, it's useful both on $2 \mathrm{D}$ and $3 \mathrm{D}$ modelling processes. In survey operations, the flight planning involving the joint use of the camera in a nadiral and oblique position, extends the field of use from the territorial scale to the archaeological and architectural one (Aicardi et al., 2016).

The use of drones gets reliable results in different high-risk situations, both for the operator safety and in inaccessible sites precluded to any "manned system" (Brumana 2013). In the archaeological field, some typical site features, such as the extension, its accessibility and the state of ruins, make drone surveys approach very fruitful both in the preliminary investigations and in the subsequent stages of analysis and representation. Moreover, the study of archaeological artefacts often presupposes the use of non-invasive methods, due to the particular fragility that generally characterizes the archaeological sites (Tsharf et al., 2015). UAV-based survey allows to obtain complete, realistic models that can be easily consulted, allowing the extraction of 2D, 3D and 4D documents (monitoring of the excavation phases) (Chiabrando et al., 2018).
UAV-based survey allows further important applications in the archaeological field for visualization, stratigraphic studies, reconstructions, structural analysis, and studies of materials and decay (Fiorillo et al., 2013). UAVs can also contribute to the realization of "archaeological maps", for the preservation of the existing heritage and as a guideline for future research (Ebolese et al., 2019). In the surveying of archaeological sites, UAVbased photogrammetry is increasingly revealing a very effective surveying strategy. Thanks also to the reduced cost compared to competing instruments, the use of drones is becoming the standard for archaeological surveys (Cowley, 2017). With due caution, today it is widely demonstrated that the results achieved in the Image Based Modeling (IBM) compete for accuracy with those obtainable from LiDAR systems, with obvious advantages in terms of accessibility as well as economic investment. Moreover, images captured by UAV through accurate path and shoot timing, allows higher control and data acquisition managing, providing to save time and resources compared to Airborne LiDAR systems (D'Auria, 2018).

\section{THE ARCHAEOLOGICAL SITE OF ANTAS VALLEY}

The research aims at the application of a workflow developed in the hypothesis of a physically inaccessible archaeological site except with the drone. Starting from this assumption, the main purpose was to lead a survey of the monument to the architectural scale through the acquisition with only the UAV camera integrated by the RTK GNSS, in order to obtain a metrically accurate three-dimensional survey model. The

\footnotetext{
* Corresponding author
} 
research has been conducted in the archaeological site of the Punic-Roman temple of Sardus Pater Babai (Figure 1) in the territory of Fluminimaggiore in south-western Sardinia.

\subsection{The case study: the Punic-Roman temple of Sardus Pater Babai}

The Sardus Pater Babai temple, also known as "Antas temple" from the toponym of the homonymous valley, is located in the territory of Fluminimaggiore. It was built on a modest relief (363 m. a.s.l.) in the south slopes of Monte Conca S'omu.

The monument, after its re-discovery by General Alberto La Marmora in 1838, was forgotten for several years and it was studied more thoroughly during the 20th century. The site of Antas has undergone profound changes over the last 50 years, mainly due to the archaeological excavation carried out since the 1960s and consequently to the anastylosis of the collapsed parts of the monument. The surrounding area, covered by a forest until the mid-twentieth century, also deeply changed due to fires and to the deforestation, making the area more easily accessible than in the past.

\subsection{The restoration and anastylosis of the temple}

Starting from the mid-twentieth century, different studies contributed to the dating and identification of two different building stages of the temple. A first Punic phase dating back to the 6th century $\mathrm{BC}$ and a subsequent Roman phase dated back to a period between $27 \mathrm{BC}$ and $14 \mathrm{AD}$ (Zucca, 1989). Between 1967 and 1968 an archaeological dig led by Prof. Ferruccio Barreca to uncover the architectural structures, bring back to light the Punic temple dedicated to the "God Sid". The excavation totally freed the podium, the outer perimeter of the roman temple steps and the side access to the Roman temple.

In 1976, Ferruccio Barreca led an important restoration project. Interrupted for about ten years and resumed in 1984, the project carried out a restoration of the collapsed portions and their anastylosis. With the partial integration of some missing parts and the installation of some concrete elements necessary for anastylosis, the temple assumed its present appearance (Zucca, 1989). In the end, the temple that we can observe today is actually the product of the interpretation of archaeologist Ferruccio Barreca, and therefore of the italian archaeological culture of the 70s. For this reason, a critical survey for the reading and analysis of the project designed and built by Ferruccio was considered to be fundamental. For this purpose, it was opportune to create a graphic documentary apparatus that involved the elaboration of 2D and 3D models, necessary for an accurate analysis of each single element of the monument.

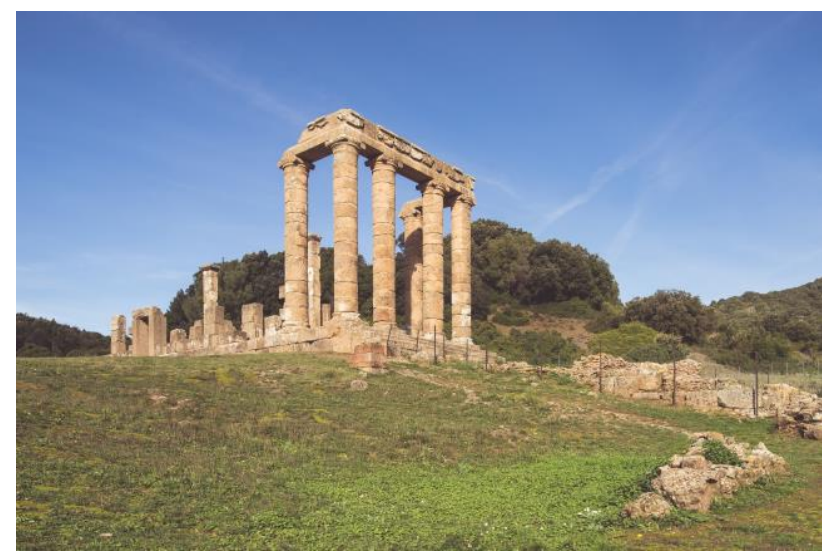

Figure 1. The temple of Sardus Pater Babai in the Antas valley

\section{METHODOLOGY}

\subsection{Overview}

Although the UAVs photogrammetric survey matches perfectly with the use of other techniques such as LiDAR systems, in a low-cost approach one of the aims of the research has been to obtain a complete survey of the temple using the strictly necessary instruments. Thanks to joint implementation of the UAV Surveying enhanced by the Global Navigation Satellite System (GNSS), it was possible to obtain a complete metrically correct model of the temple.

Aimed at producing a 3D Model of the monument, a Digital Elevation Model (DEM) of the area and 2D representations from orthophotos of plans, elevations and cross sections, the workflow is expressed through the three classic phases of survey plan, data acquisition and data processing (Figure 2).

Consistent with the philosophy of a low-cost approach, the choice has fallen into using a DJI Spark, a consumer drone with sufficient standards to guarantee a quality in accordance with the aims of the research. It is a mini drone: measuring $143 \times 143 \times 55 \mathrm{~mm}$ and weighs, thanks to the modifications made, only 300 grams. The Spark DJI drone guarantees however high performances that can bring the aircraft up to over $50 \mathrm{Km} / \mathrm{h}$. The $1480 \mathrm{mAh}$ battery allows however flights of only 16 minutes in optimal conditions and constant speed.

The drone was equipped with a $1 / 2.3$ "sensor camera, $6.17 \mathrm{x}$ $4.56 \mathrm{~mm}, 12$ mega-pixel (3968 x 2976) and with a focal length of the camera lens of $4.49 \mathrm{~mm}$ (25mm equivalent) which in photo mode covers a field of view (FOV) of $81.9^{\circ}$.

Data processing was carried out with the Agisoft Metashape software according to the classic workflow because of its proven validity and accuracy (Sona et al., 2014).

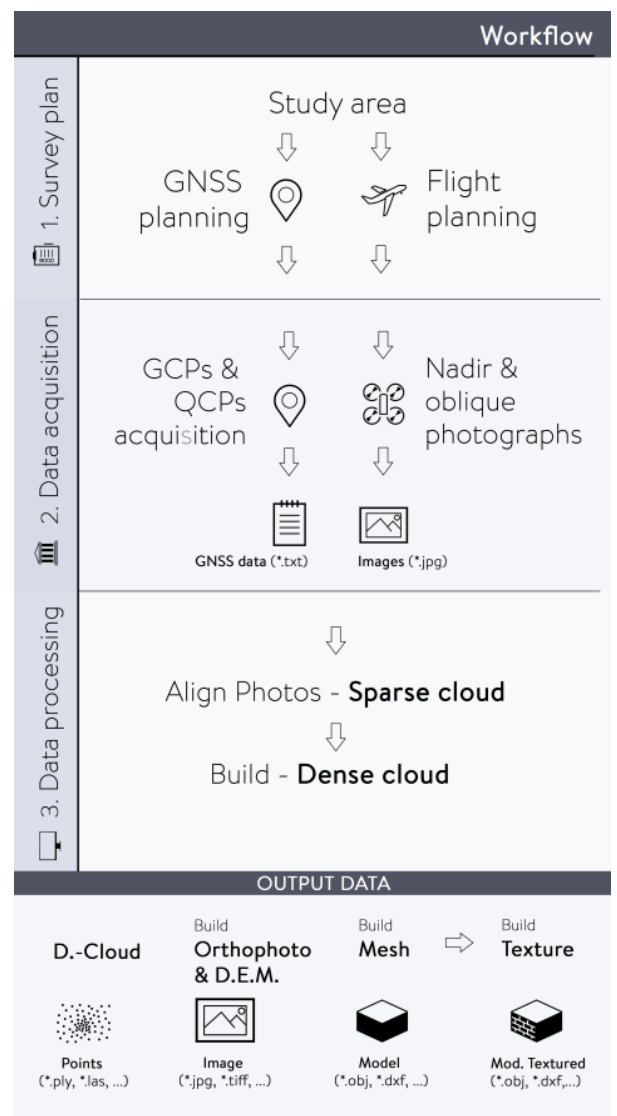

Figure 2. Workflow and output data 


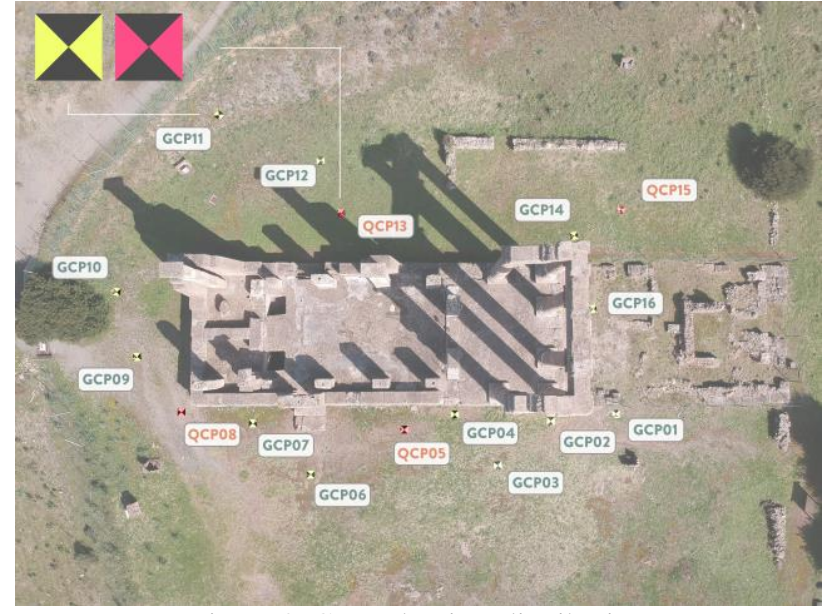

Figure 3. Control points distribution

\subsection{Data acquisition}

3.2.1 GNSS Survey: The integrated use of the most conventional system of the Global Navigation Satellite System (GNSS) reinforces the data derived from images and offers validation and quality control of the work; furthermore, the integration of this system allows for a georeferenced 3D model. The setting of the survey has included a preliminary study aimed at defining the number and position of the markers: this step is particularly important in order to achieve an optimal result (Villanueva and Blanco, 2019). The GNSS survey was performed with a Magellan Promark 500 in Real-Time Kinematic mode. A set of 16 chromatically differentiated targets was chosen, divided into two groups. A first set of markers consists of 12 Ground Control Points (GCPs), useful for the optimization of the survey and the reduction of root-meansquare error (RMSE). A second set of 4 Quality Control points (QCPs) has been adopted for checking the quality of the model. The markers were placed over the entire area, with a uniform but not regular distribution, around the temple and keeping the QCPs placed at a certain distance from each other (Villanueva and Blanco, 2019). The drone flights were performed after recording the system of control points (Figure 3 ).

3.2.2 UAV Acquisition: Taking up the principle of the "Maltese Cross" configuration (Aicardi, 2016), the flight plans were programmed according to nadiral and oblique photographs. Both nadiral and oblique shots allow for a effective study of the site with a better documentation of the architectural structures elevation. The "Maltese Cross" system includes a pointing camera in a nadiral position and four oblique pointing cameras: two oblique cameras point in opposite directions while the other two oblique points in the opposite along-track directions (Petrie, 2009).

The flight plan was designed on the free "Red Waypoint" software, which allows autonomous operations to the DJI Spark. Traced according to a crossed grid, the nadiral shots cover the entire area occupied by the temple with the gimbal set in a nadiral position and constant heading throughout the flight. This first series of photographic shots gives the best view of the upper surfaces of the monument, which corresponds to an excellent horizontal accuracy and a low definition of the elevations. The nadiral shots, taken at a constant flight altitude of 15 meters above the ground, follow a cross-mesh grid that covers the entire area of the temple, with the gimbal set in a nadiral position and constant heading throughout the flight.
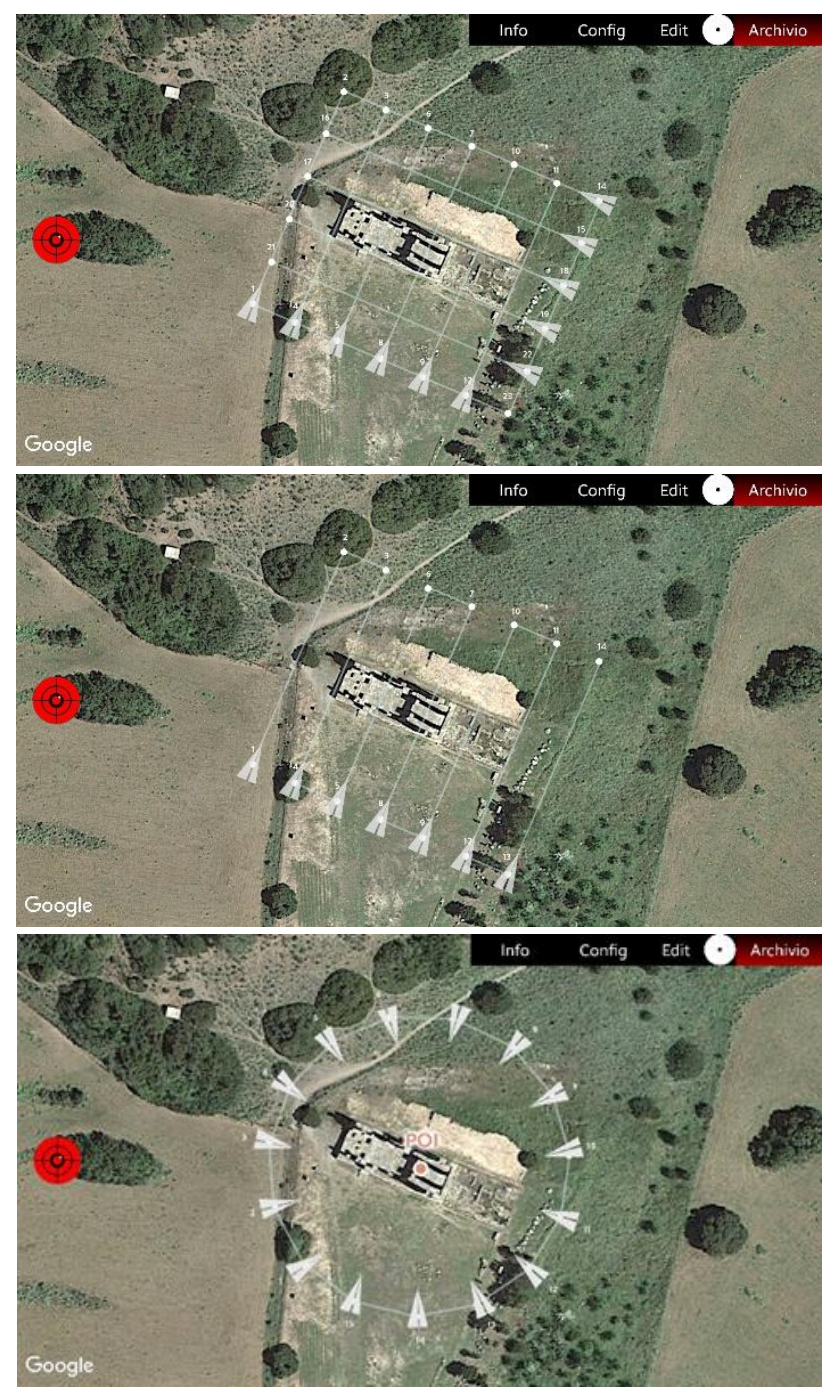

Figure 4. Flight plans with Red Waypoint. Nadir flight (up), oblique-N-S flight (middle) and the oblique-circular one

(down).

The speed of the vehicle and the interval of the shutter have been programmed to obtain a cross and along overlap of $80 \%$. The oblique shots have a plan of four flights covering the entire area with the camera set on a $45^{\circ}$ angle (Rossi et al. 2017; Chiabrando, 2017).

The oblique shots greatly increase the quality of vertical surfaces, helping they also to align the nadiral photographs with those images taken from lower points of view. The oblique shots, also performed at a height of 15 meters, provided four flights of parallel bands, each one covering the entire area and elevation of the monument, with a different heading setting at a 90-degree angle to each other.

To complement the "Croce Maltese" configuration, an orbit at low altitude (6 meters) was finally performed around the monument with an inclination of the camera of about 20 degrees. This last series of images was taken along a circular trajectory around the temple maintaining the direction of the camera oriented towards the Point-Of-Interest (POI), with the camera tilted about $20^{\circ}$. These last images are also aimed at optimizing the rendering of the model in the vertical direction of restitution, taking the monument's elevation from new useful directions (Figure 4). 


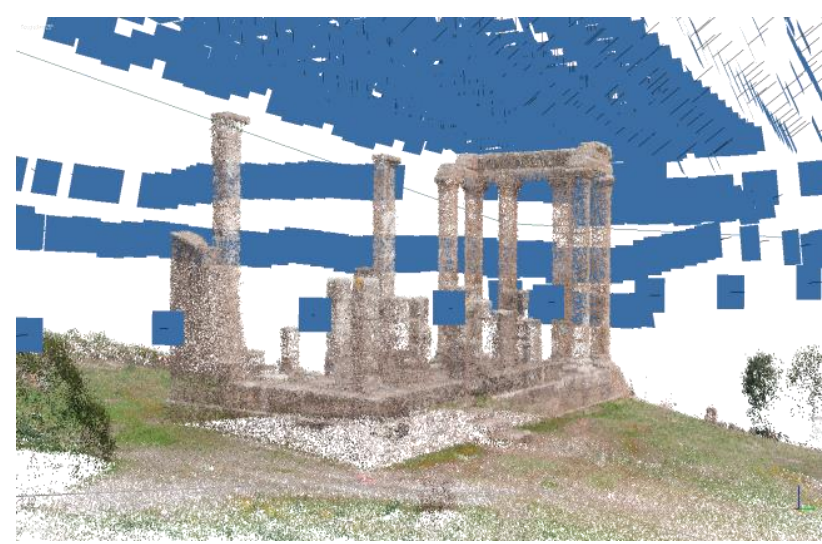

Figure 5. Camera position and sparse cloud

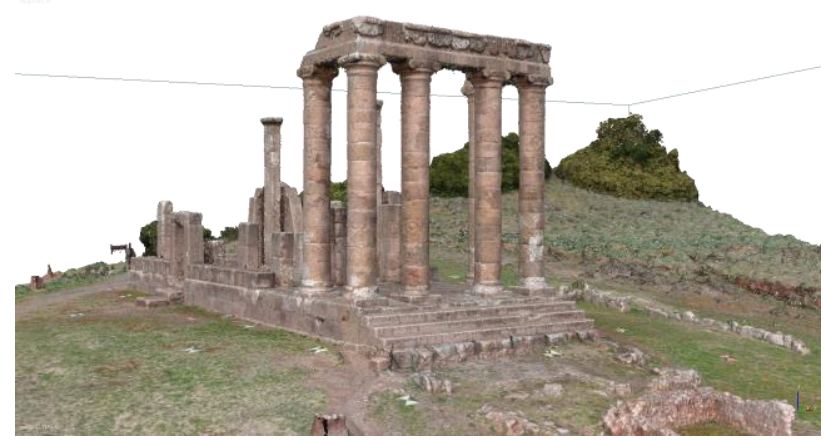

Figure 6. Dense cloud

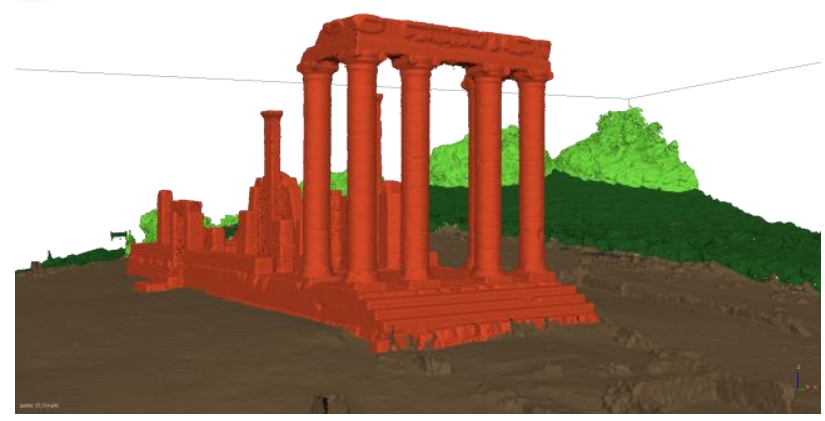

Figure 7. Dense cloud classification

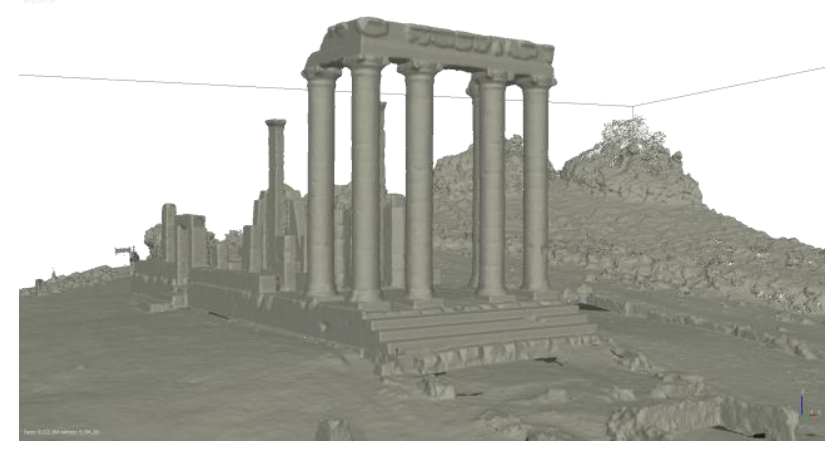

Figure 8. 3D mesh model

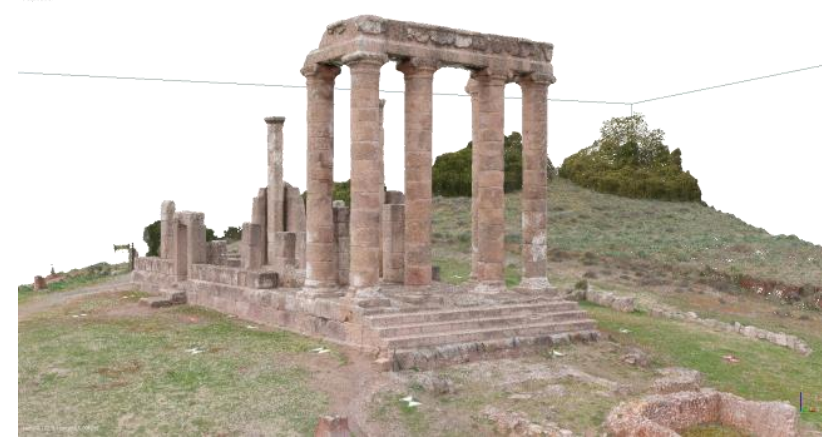

Figure 9. 3D textured mesh model

\subsection{Data processing}

Once acquired drone-based image data, the successive step has provided for data processing. In order to evaluate the goodness of the photographs, despite the extreme care given in the camera settings, we decided to use the automatic image quality estimation feature (Agisoft Metashape). After adding and verifying the images, defining homologous points (tie points) from recognizable elements (key points), we proceeded with SfM camera positions and orientation (Agisoft, 2018).

The sparse cloud resulting from the SfM process is made up of 1,685,299 points (Figure 5). This cloud was treated by eliminating outliers and incorrectly projected points. The input of the GPS coordinates, correcting the non-linear deformations with the optimization tool, allowed a validation of the metric information of the survey. Identifying the markers, entering the cartographic coordinates and optimizing the alignment, the dense cloud consisting of 241,579,643 points was built (Figure 6). Furthermore, the dense cloud was processed with the free Cloud Compare software (subsample, noise reduction and "SOR Filter").

For a lean management of the successive phases of the process, the dense point cloud has been classified to be able to manage individually the different categories of points (i.e. road surface, low vegetation, high vegetation, ground, building) (Figure 7).

In the elaboration of the 3D mesh model (Figure 8), the classification of the points made it possible to distinguish the wall surfaces of the monument from the surfaces of the ground and vegetation. This distinction allowed to achieve maximum accuracy on temple surfaces. The Texturing phase completes the construction of the 3D mesh model (Figure 9).

The study of an archaeological site such as the Temple of Antas requires a detailed analysis of the individual elements. Each constructive element must be considered as the sum of several elements resulting from the the "anastylosis" designed and conducted by Ferruccio Barreca. For this purpose, it was necessary to isolate the single elements to make possible a local analysis aimed at the reconstruction of the archaeological design process.

A semantic classification was subsequently performed in order to organize a database for an effective consultation. The different elements that make up the structures of the Roman temple was analysed and isolated in order to study the anastylosis of the architectural order and, in the first instance, its rules. The model was segmented into different parts on Agisoft Metashape software and then each one was exported individually in * obj format.

Considering the columns, base, capital and the individual drums of the shaft, were detached and then recomposed within the Rhinoceros 6 software (Figure 10 and Figure 11). 


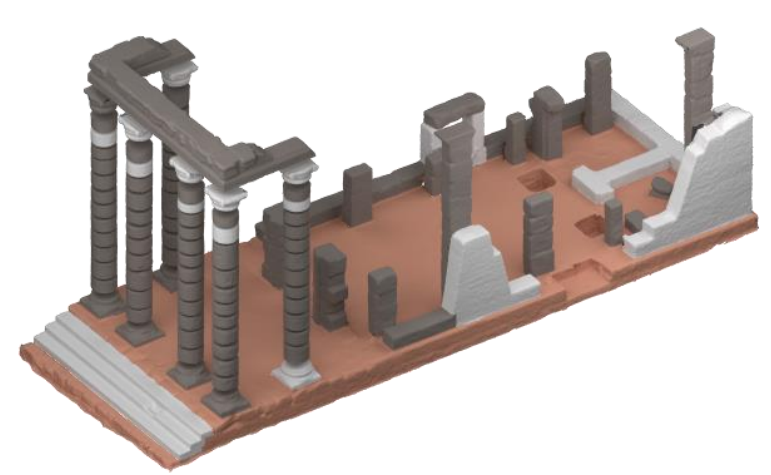

Figure 10. Semantic classification of the temple constructive elements

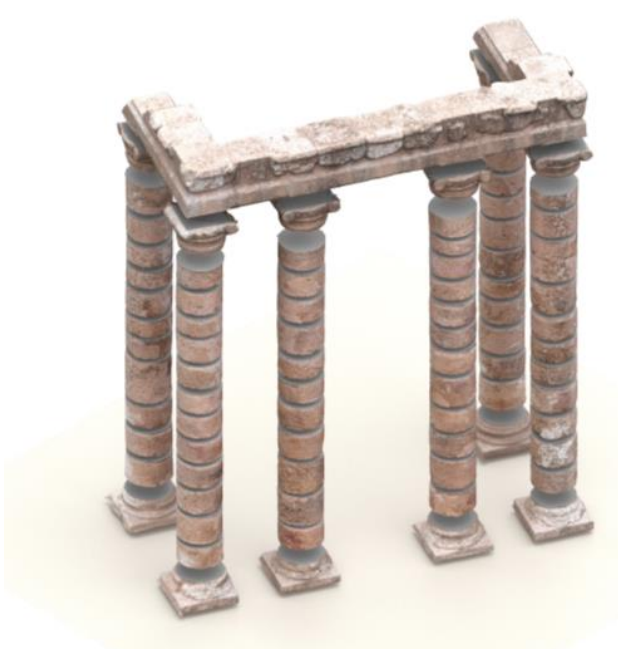

Figure 11.3D textured mesh model: colonnade segmentation

At the end of the process, the root square error [RMSE $(\mathrm{cm})]$ of the check points projection indicates a value in Reference of $2.92074 \mathrm{~cm}$ (Table 1).

The use of the GNSS system has further enhanced its metric value by obtaining a RMSE error index verified in the QCPs of $1.59,2.22$ and $1.03 \mathrm{~cm}$ respectively in the $\mathrm{X}, \mathrm{Y}$ and $\mathrm{Z}$ axes; a satisfactory result for the analysis on the architectural scale of the monument. The orthophotos, with a resolution of $6.29 \mathrm{~mm} /$ Pix, were found to be an excellent basis for restoring and analyzing the anastylosis carried out by Ferruccio Barreca.

The Digital Elevation Model (DEM) and the orthomosaic of the area (Figure 12) were extracted in GeoTIFF, a georeferenced image, with a size of $7697 \times 7693 \mathrm{px}$, with a resolution of 1.26 $\mathrm{cm} / \mathrm{px}$, over an interval between 404 and 422 meters a.s.l.

\begin{tabular}{|c|c|c|c|c|}
\hline \multicolumn{2}{|c|}{$\begin{array}{c}\text { Number of GCPs } \\
\text { /QCPs }\end{array}$} & \multicolumn{3}{|c|}{ RMSE (cm) } \\
\cline { 3 - 5 } & $(\mathrm{XY})$ & $(\mathrm{Z})$ & (Total) \\
\hline GCPs & 12 & 2.48 & 1.70 & 3.01 \\
\hline QCPs & 4 & 2.73 & 1.03 & 2.92 \\
\hline
\end{tabular}

Table 1. RMSE residuals of GCPs and QCPs.

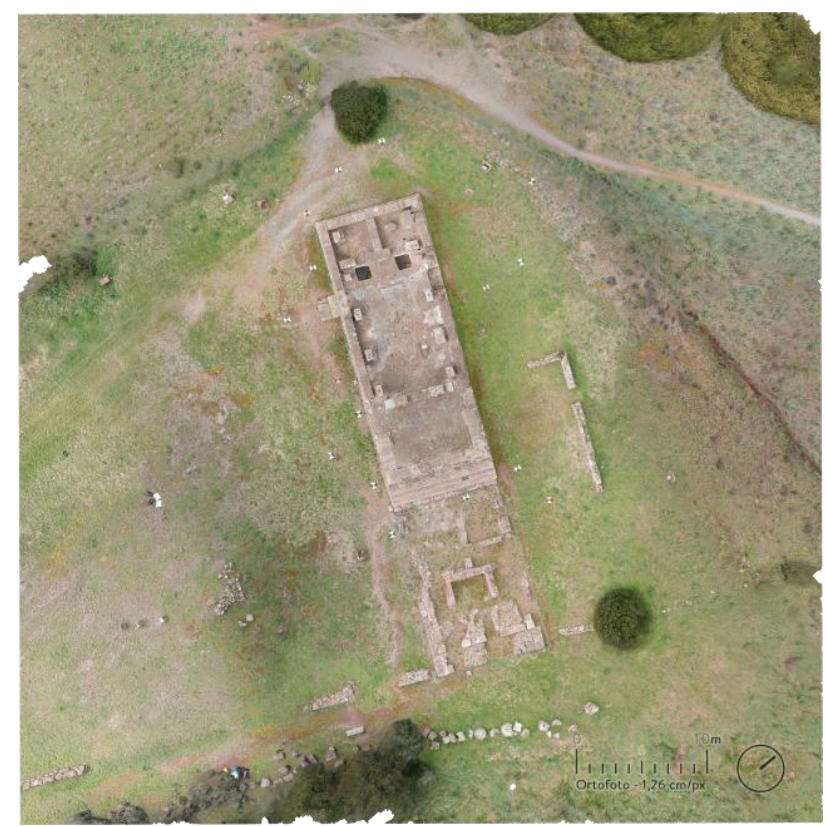

Figure 12. Orthomosaic of the area

\section{CONCLUSIONS}

The paper presents the first results of an ongoing research aimed at the application of UAV photogrammetry processes on archaeological sites. The project carried out on the Temple of Antas has confirmed our initial assumptions even though the limits of a consumer drone, limits that can be exceeded thanks to an accurate survey planning. The short battery life was resolved by splitting flight plans into 9 -minute missions, so as to ensure safe landing with a conservative remaining charge. The use of "Red Waypoint" software, instead of the one developed by DJI for the Spark, has compensated for the vehicle shortcomings which, from the factory, did not allow for total management of the autonomous flight. The relatively low resolution of the camera was managed by keeping a distance from the structures lower than the one necessary with a higher quality camera. One of the purposes of the UAV-based survey of the temple was to derive a comprehensive base useful for the development of further investigations in the archaeological field and on the architecture of the monument.

The adoption of a low-cost approach becomes fundamental in the hypothesis of a possible application also in the didactic field. The use of the GNSS system has conferred greater dimensional solidity to the model, allowing an analysis of accuracy and, thanks to georeferentiation, offering the possibility of further research developments by entering the survey in a GIS environment and integrating the knowledge of $3 \mathrm{D}$ and $2 \mathrm{D}$ assets.

Thanks to the use of oblique camera and low-altitude orbits, the 3D model possesses an accuracy and a resolution that are well suited to different applications, such as stratigraphic studies, structural analysis, materials and decay studies, or the development of reconstructive hypotheses, as well as an excellent visualization tool (Figure 13). 


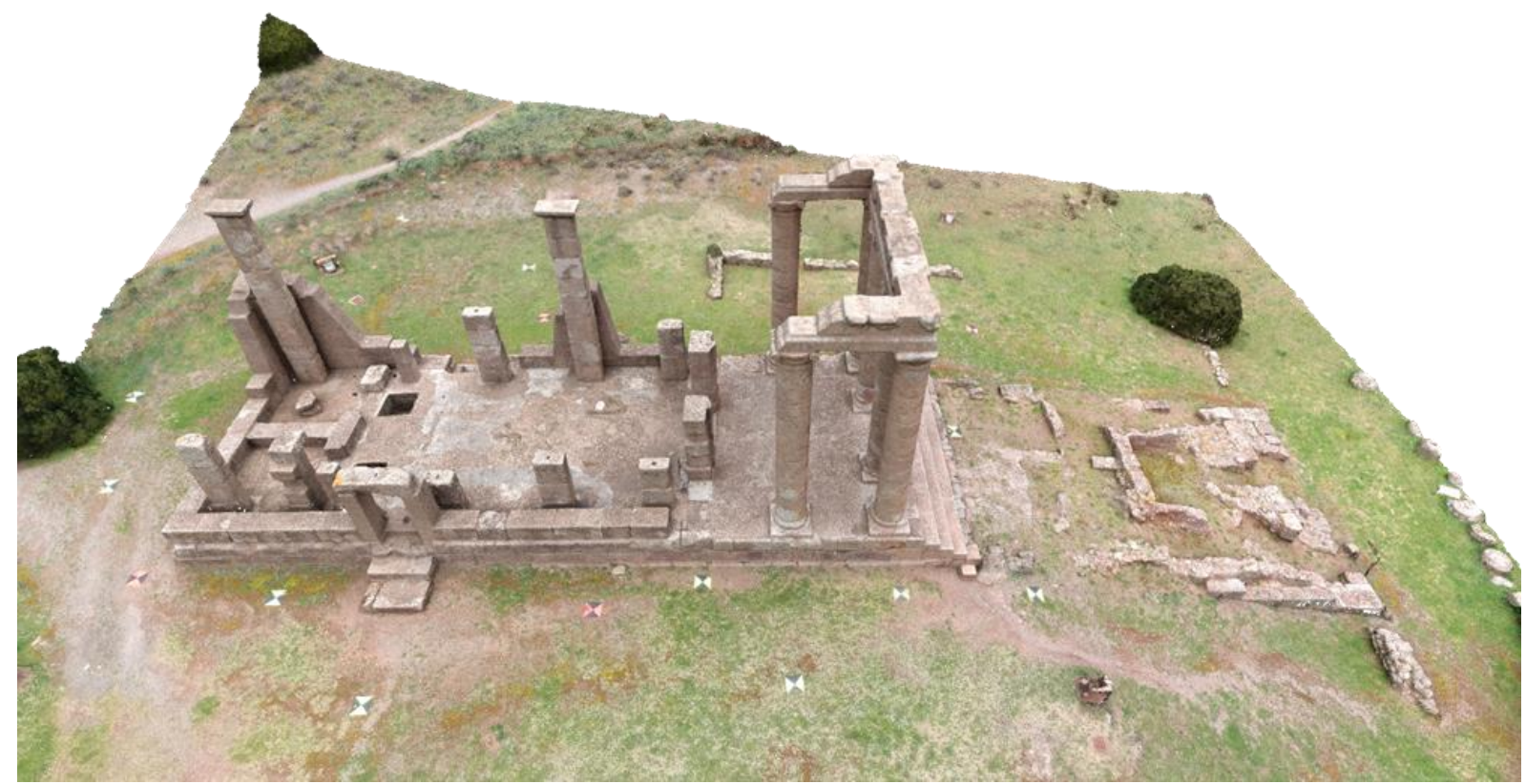

Figure 13. 3D rendering of the final model

\section{ACKNOWLEDGEMENTS}

For the realization of this work the authors would like to express their gratitude to Dott. Massimo Casagrande of the "Sopraintendenza Archeologia, belle arti e paesaggio per la città metropolitana di Cagliari e le province di Oristano e Sud Sardegna". A special thank is due to the staff of "Start-Uno" society that manages the archaeological site of Antas.

\section{REFERENCES}

Agisoft LLC., 2018: Agisoft Metashape User Manual Professional Edition, Version 1.5.

Aicardi, I., Chiabrando, F., Grasso, N., Lingua, A. M., Noardo, F., and Spanó, A. 2016: UAV photogrammetry with oblique images: First analysis on data acquisition and processing. In: The International Archives of the Photogrammetry, Remote Sensing and Spatial Information Sciences, Vol. XII, 835-842. doi.org/10.5194/isprsarchives-XLI-B1-835-2016.

Barreca, F., 1976: Il Tempio di Antas e il culto di Sardus Pater.

Brumana, R., Oreni, D., Van Hecke, L., Barazzetti, L., Previtali, M., Roncoroni, F., and Valente, R., 2013: Combined geometric and thermal analysis from UAV platforms for archaeological heritage documentation. ISPRS Ann. Photogramm. Remote Sens. Spatial Inf. Sci., II-5/W1, 49-54.

Chiabrando, F., Lingua, A., Maschio, P. and Teppati Losè, L. 2017:. The Influence of flight planning and camera orientation in UAVs photogrammetry. A test in the area of Rocca San Silvestro (LI), Tuscany. ISPRS - International Archives of the Photogrammetry, Remote Sensing and Spatial Information Sciences, XLII-2/W3, pp.163-170.

Chiabrando, F., D'Andria, F., Sammartano, G. and Spanò, A., 2018: UAV photogrammetry for archaeological site survey. 3D models at the Hierapolis in Phrygia (Turkey). Virtual Archaeology Review, 9(18), p.28.

Cowley, D. C., Moriarty, C., Geddes, G., Brown, G. L., Wade, T., and Nichol, C., 2017: UAVs in Context: Archaeological Airborne Recording in a National Body of Survey and Record. Drones, vol. 2, Issue 1, 1-16.

D'Auria, S., 2018: User-friendly and low-cost photogrammetry for dissemination of 224 cultural heritage: digital reconstruction of the Gothic portal of the Church of Sant'Eligio al Mercato in Naples. Unione italiana per il disegno Rappresentazione/Materiale/Immateriale, pp.503 - 506.

Ebolese, D., Lo Brutto, M. and Dardanelli, G., 2019: Uav survey for the archaeological map of Lilybaeum (Marsala, Italy). ISPRS - International Archives of the Photogrammetry, Remote Sensing and Spatial Information Sciences, XLII2/W11, pp.495-502.

Fernández-Hernandez, J., González-Aguilera, D., RodríguezGonzálvez, P., Mancera-Taboada, J., 2015: Image-Based Modelling from Unmanned Aerial Vehicle (UAV) Photogrammetry: An Effective, Low-Cost Tool for Archaeology Applications. Archaeometry, 57 (1), 128-145.

Fiorillo, F., Jiménez Fernández-Palacios, B., Remondino, F., \& Barba, S. (2013). 3D Surveying and modelling of the Archaeological Area of Paestum, Italy. Virtual Archaeology Review, 4(8), 55-60. doi:10.4995/var.2013.4306

Furukawa, Y., and Ponce, J., 2010: Accurate, dense, and robust multiview stereopsis. IEEE Transactions on Pattern Analysis and Machine Intelligence, Vol. 32(8), pp. 1362-1376. https://doi.org/10.1109/TPAMI.2009.161

Javernick, L., Brasington, J., and Caruso, B., 2014: Modeling the topography of shallow braided rivers using Structure-fromMotion photogrammetry. Geomorphology, Vol 213, pp. 166182. https://doi.org/10.1016/j.geomorph.2014.01.006 
Petrie, G., 2009: Systematic oblique aerial photography using multi frame cameras. Photogrammetric Engineering \& Remote Sensing, 75(2), pp. 102-108.

Rossi, P., Mancini, F., Dubbini, M., Mazzone, F. and Capra, A., 2017: Combining nadir and oblique UAV imagery to reconstruct quarry topography: methodology and feasibility analysis. European Journal of Remote Sensing, 50(1), pp.211221.

Sona, G., Pinto, L., Pagliari, D., Passoni, D., and Gini, R., 2014: Experimental analysis of different software packages for orientation and digital surface modelling from UAV images. Earth Science Informatics, 7(2), pp. 97-107. https://doi.org/10.1007/s12145-013-0142-2

Tscharf, A., Rumplerb, M., Fraundorferb, F., Mayera, G., Bischofb, H., 2015: On the Use of UAVs in Mining and Archaeology - Geo-Accurate 3D Reconstruction Using Various Platforms and Terrestrial Views. In: ISPRS Annals of the Photogrammetry, Remote Sensing and Spatial Information Sciences, Vol. II-1/W1, pp. 15-22.

Villanueva, J.K.S. and Blanco, A.C., 2019: Optimization of Ground Control Point (GCP) configuration for Unmanned Aerial Vehicle (UAV) Survey using Structure from Motion. ISPRS - The International Archives of the Photogrammetry, Remote Sensing and Spatial Information Sciences, XLII4/W12, pp.167-174.

Westoby, M.J., Brasington, J., Glasser, N.F., Hambrey, M.J., Reynolds, J.M., 2012: Structure-from-Motion' photogrammetry: a low-cost, effective tool for geoscience applications.

Zucca, R. 1989. Il tempio di Antas. Sassari: Delfino. 